\title{
Conceptual Design of a Digital Shadow for the Procurement of Stocked Products
}

\author{
Daniel Pause, Matthias Blum \\ Institute for Industrial Management (FIR), Aachen, Germany \\ \{daniel.pause\}@fir.rwth-aachen.de
}

\begin{abstract}
Industrie 4.0 and the consequent necessity of digitalization has also implications to the field of procurement, resulting in the so-called term of Procurement 4.0. Digitalization can be a valuable tool to increase the efficiency of the procurement organization and to exploit new opportunities of growth. A mandatory requirement to perform the digital transformation is an increased transparency along the procurement process chain. This paper aims to conceptualize a digital shadow for the procurement process in manufacturing industry as a basis for advanced data analytics procedures. The term digital shadow stands for a sufficiently accurate, digital image of a company's processes, information and data. This image is needed to create a real-time evaluable basis of all relevant data in order to finally derive recommendations for action. The formation of the Digital Shadow is thus a central field of action for Industrie 4.0 and forms the basis for all further activities.
\end{abstract}

Keywords: Procurement 4.0 • Digital Shadow • Data Analytics • Conceptual Data Model $\bullet$ Industrie $4.0 \cdot$ Digital Supply Chain

\section{Introduction}

The rigid value chains are being transformed into highly flexible value networks. This lays out the platform for the end-to-end digitalization of the entire value chain [1]. Being a part of the value chain, procurement also has to adapt itself to the transformation of Industrie 4.0. As procurement acts as a direct interface between the company and suppliers, it holds the advantage of bringing the innovations into the company. This creates the opportunity for procurement to establish a better position within the entire network, both inside and outside of the company. This will result in the increase of the strategic importance of procurement. The digital transformation and the real-time availability will henceforth lead to the introduction of Procurement 4.0 [2].

"Procurement 4.0" or a "Supply Management 4.0" is a fundamental conceptual element of Industrie 4.0 as it connects the different supply chain partners and enables a dynamic and rapid cooperation and coordination beyond organizational boundaries [3]. To achieve this cooperation and coordination and to also improve the corporate processes, the company's data und their transparency is very essential. Therefore real-time as well as historical data must be evaluated. An exact digital mapping of all processes, information and data of a company is necessary. This digital mapping is called Digital Shadow [4]. In this paper we focus on the digital shadow for the procurement process in manufacturing industry.

The field of observation in this paper is the procurement of stocked products, for example C-parts. The ABC analysis is based on the finding that typically a relatively small percentage of goods in the warehouse make up a high proportion of the total inventory value. Typically, about $20 \%$ of the stock accounts for $70-80 \%$ of the total inventory value (Aparts). Another $10-15 \%$ of the stock value is tied by another $30 \%$ of the stock quantity (Bparts). The remaining $10-15 \%$ are represented by the C-parts, which usually account for about $50 \%$ of the amount [5]. The cost of procuring C-parts in comparison to the value of goods is usually disproportionately high. Ordering, warehousing, administration and internal goods movement often generate $80 \%$ of the costs, only $20 \%$ correspond to the material value [6]. Increased transparency in the procurement process by means of a digital shadow may be helpful to reduce procurement and storage costs of C-parts. 
The remainder of this paper is organized as follows: First, a brief description about the impact of Industrie 4.0 on the procurement organization is given. The second chapter deals with the motivation for deriving a digital shadow for the Procurement of Stocked Products. In section 3, the state of the art of a digital shadow as a basis for data analytics in the context of business intelligence is described and Section 4 derives a digital shadow based on corporate reference processes. Finally, we conclude in Section 5 and highlight future work.

\section{Motivation}

In this paper, the term analytics in association with business intelligence is defined as follows: It is understood as a scientific process of mathematical-logical transformation of data to improve decision making [7]. Depending on the maturity level of analytical skills, four stages of data analytics can be defined: descriptive, diagnostic, predictive and prescriptive analytics (see figure 1) $[8,9]$.

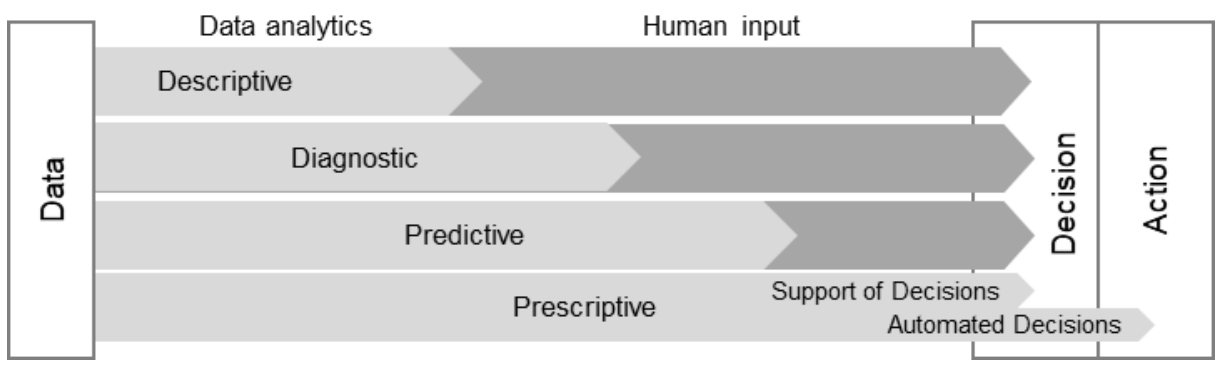

Fig. 1. Four stage model of the decision making assisted by data analytics [8]

The first stage, called descriptive analytics, answers the question "What happened?". Descriptive analytics aim at analyzing large amounts of data with the purpose of getting an insight and conclusion of what happened in the past. By analyzing interactions within the data diagnostic analytics pursue the question "Why did it happen?". Predictive and prescriptive analytics support proactive optimization. The question "What will happen?" is covered by predictive analytics. Future behavior is predicted by methods of pattern recognition and the use of statistics. Prescriptive analytics form the last stage and answer the question "What should be done?". Using optimization algorithms and simulation approaches concrete measures are suggested or even directly implemented without any human interaction [8].

In this paper the following research question will be answered: How can we increase transparency in cross-company procurement networks using the concept of the digital twin?

\section{State of the Art}

Although, several publications focus on approaches regarding data models which assist in planning and controlling the manufacturing process, a scientific investigation of a realtime representation of a product component in a procurement stage is only performed in very few research activities and not dealt with in detail. In the following section these approaches will be outlined.

The paper by the research corporation for production technology defines the Digital Shadow as a sufficiently exact mapping of processes in the production and development with the objective to create a basis that evaluates in real-time all relevant data. As a main challenge the paper points out the determination of the relevant data. It especially focusses on the state of technology and the corresponding challenges. In that sense the research corporation refers to multimodal data acquisition and data fusion as a means to achieve data faster and in a more reliable way. In contrast to our research, this research does no create a model to illustrate the minimum level of transparency which is required to put Procurement 4.0 into practice [10]. 
Schuh et al. emphasize in their paper the huge relevance that the Digital Shadow currently has in the production processes. Relating it to Industry 4.0 the paper points out that the Digital Shadow gained more importance following the development of Industry 4.0 as better possibilities to link and process data. Within the framework of digitalization not only the generation of data but especially its efficient use gains more importance. For the production process the relevant data can help to measure efficiency and progress and initiate changes. In the following the paper focusses on explaining how companies can create a Digital Shadow using the method of a migration path. This concept analyses the available and needed data and decides on the corresponding technology. In contrast to our paper, it consequently describes an approach to implement to corresponding technology while we focus on a conceptual data model [4].

Blum \& Schuh define the Digital Shadow as a virtual representation of a product on the shop-floor that represents the relevant data in real-time. They focus on using real-time data as in other relevant papers concerning data models real-time data is neglected. As in our research, the paper also develops a data structure but they do not use the conceptual data model and they focus on order processing and do not consider procurement [11].

\section{Deriving a digital shadow for procurement process}

The methodology for deriving a digital shadow for the procurement of stocked products, as a first step, central business processes have to be defined. The SCOR model will be used as a regulation framework to derive basic business processes, related to stocked products. The second step comprises the derivation of a data structure as a basis for data analytics. To visualize the datastructure a conceptual data model will be used. This data model is a conceptual representation of data structures required to construct a database and a crucial tool to illustrate business requirements. However, hardware and software requirements are not considered.

\subsection{Defining Processes in Procurement}

As pointed out before, the first step before creating a data structure as a basis for data analytics procedures is defining the corporate processes in the field of procurement. The Supply Chain Operations Reference (SCOR) model by APICS SCC ${ }^{1}$ is used as a reference model to define the basic procurement processes (see figure 2).

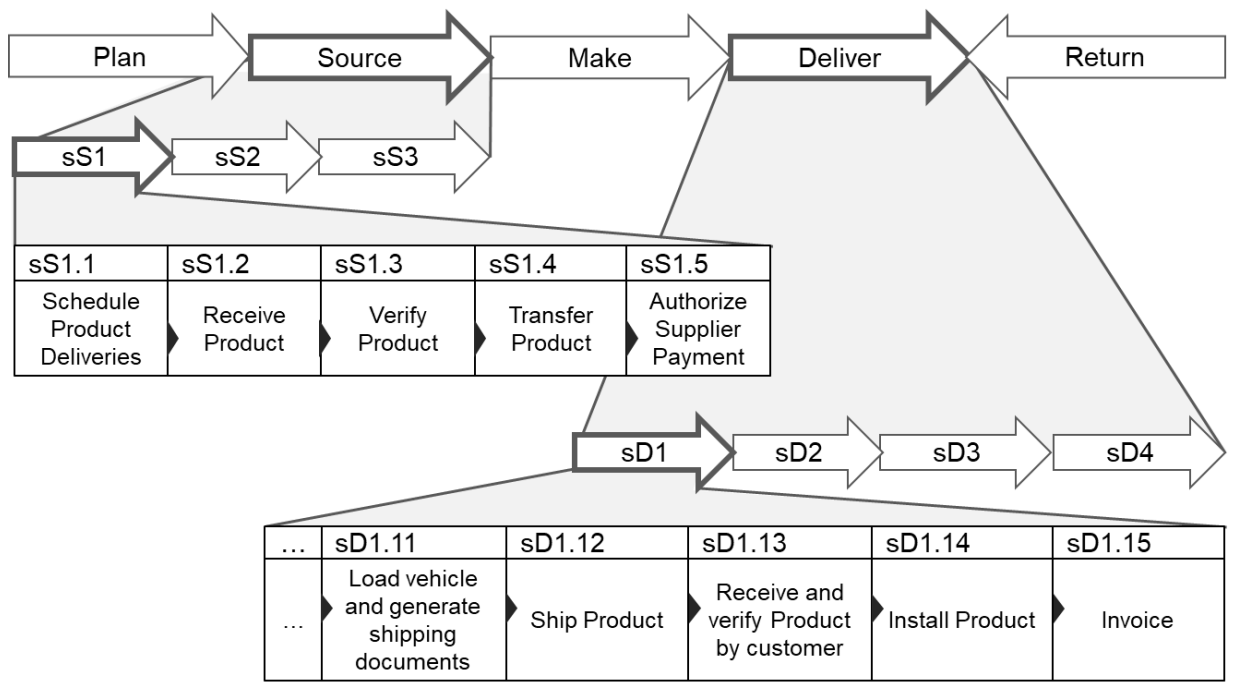

1 "APICS Supply Chain Council (APICS SCC) is a nonprofit organization [...] that maintains the Supply Chain Reference model (SCOR), the supply chain management community's most widely accepted framework for evaluating and comparing supply chain activities and performance." [12]. 
Fig. 2. "Source" and "Deliver" Processes of the Supply Chain Operations Reference (SCOR) model

The SCOR model comprises different schematic process levels. The first level gives a definition of the scope and content of the SCOR model and the second level differentiates different configuration types. The third level finally describes operational processes. In Figure 2 , only the "source" and "deliver" processes relevant to the context of the work are presented in greater detail.

The field of "Source" is differentiated in different configuration types such as "Source Stocked Product" (sS1), "Source Make-to-Order Product" (sS2) and "Source Engineer-toOrder Product" (sS3). In the following, the configuration type of stocked products (sS1) will be considered. It is described as a "process of ordering, receiving and transferring raw material items, sub-assemblies, product and or services based on aggregated demand requirements. The intention of Source-to Stock is to maintain a pre-determined level of inventory for these materials, sub-assemblies or products. No customer reference or customer order detail is exchanged with the supplier, attached to or marked on the product, or recorded in the warehousing or ERP system for Source-to-Stock products." [12]

Since the procurement process represents the external boundary of the enterprise and communicates with external actors in the supply chain, the distribution process of the supplier or logistics service provider should also be considered. For this reason, the important processes regarding product shipping are listed. The configuration types within the field of "Deliver" are similar to "Source", however, there is an additional configuration type "Deliver Retail Product" (sD4). In the following, the configuration type of stocked products (sD1) will be considered. It is described as a "process of delivering a product that is sourced or made based on aggregated customer orders and inventory re-ordering parameters." [12]

\subsection{Data structure as a basis for data analytics}

\section{Physical level}

According to the understanding of a production process, the process consists of different process steps which are needed to procure a product. Items are tracked in relation to the procurement plan, e.g., the transport vehicle. This enables the user to determine on which transport operations have been performed to complete the order. Based on the current operation the status of the order is logged. To calculate time related data (e.g. absolute procurement time, transition time) the status is needed. With this information conclusions about the current state of an order as well as ex post analysis are conducted. Based on the data record orders with the same production processes can be compared and reasons for deviations can be revealed.

\section{Virtual level}

This section presents the derived data structure for the virtual representation of the transported goods during the procurement process as a basis for data analytics. For a comprehensive representation of an order in the purchasing department different aspects have to be considered. Besides tangible aspects (e.g. the good, transport vehicles, etc.) intangible aspects (e.g. purchasing plans, the geolocation, the status, etc.) are needed. The data structure is primarily developed for procuring stocked products. The derived data structure is presented in figure 3 and is described hereafter. 


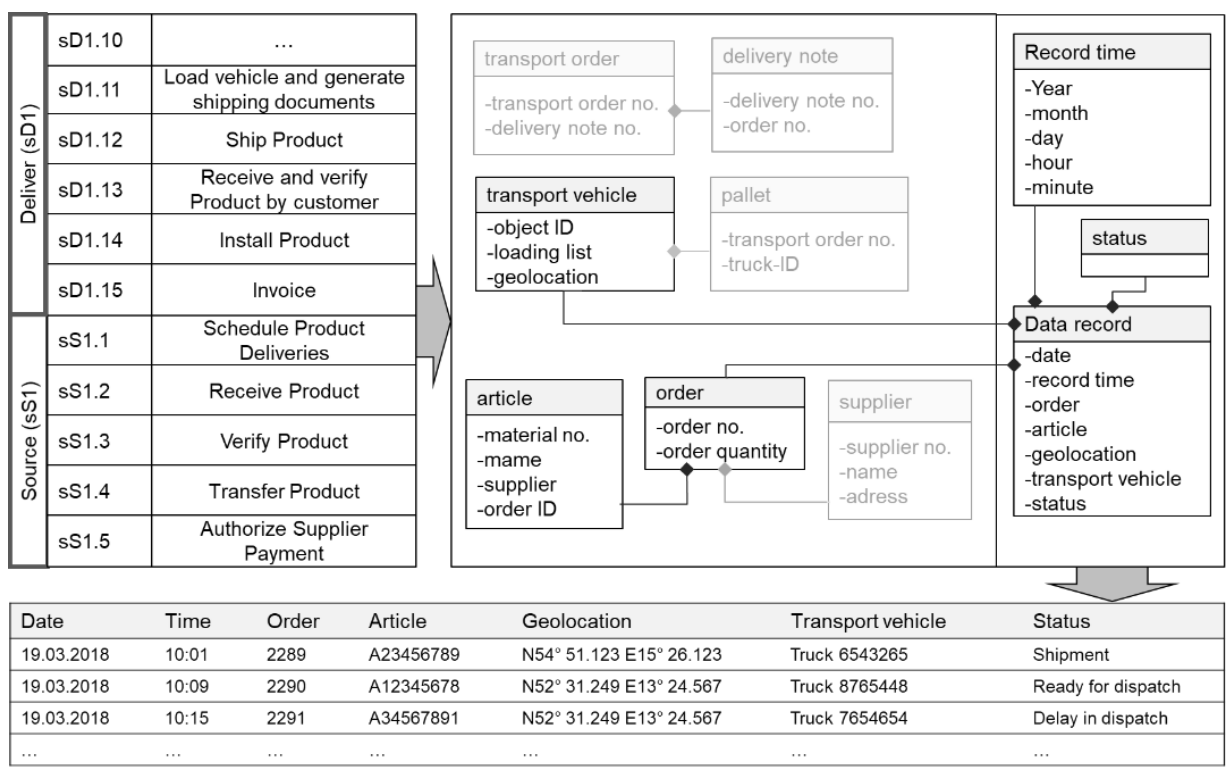

Fig. 3. Data structure for the purchasing of stocked products including example data sets

Time data specifies when the data was recorded and enables an entire data record from the start of monitoring until all processes are executed. Similar to an airplane's flight data recorder collected data is written inside a database in a specific time interval. As time data constitutes the leading characteristic among the collected data, corresponding data must refer to it. During the procurement process deviations from the schedule (e.g. geolocation and transport vehicle) may occur and can be detected in real-time. Order data includes the attributes order and product. The item order assigns a unique ID to each order and enables the traceability of an order during the procurement and delivery process. Furthermore, product ID is recorded to determine between different products of an order. Based on the integration of tracking technologies (e.g. GPS) a live tracking of an order is possible. Tracking the geolocation is necessary in order to ensure the routing of the order between two points. This enables to determine the current location of the order. Featured by the use of sensor technologies and a real-time routing, the status of an order between different steps in the procurement plan can be obtained.

\section{$5 \quad$ Conclusion and further research}

In this research paper a data structure for the procurement of stocked products is developed, which aims at providing a virtual representation of the transported goods during the procurement process. The digital shadow represents the relevant data (e.g., order, geolocation and status) in a time series format. After introducing the relevant processes for the procurement the structural framework of a data structure was derived. For enabling the implementation of the model, practical implications have been carried out. This data structure is the foundation for the use of data analytics methods in the procurement environment. Therewith, conclusions about past incidents and a real-time status of an order contribute to improve procurement processes. Further research is needed to substantiate the presented solution principles. Directions of further work include the development of measures to improve the data quality (i.e., plausibility and consistency checks and the use of information provided by sensors), the handling of the geolocation and the development of a reference architecture.

Acknowledgements. The presented research is a result of the Cluster of Excellence $(\mathrm{CoE})$ on "Integrative Production Technology for High-Wage Countries" funded by Deutsche Forschungsgemeinschaft (DFG). Within the CoE "Integrative Production Technology for High-Wage Countries" several institutes at RWTH Aachen University are conducting research on fundamentals of a sustainable production strategy. The authors would like to 
thank the German Research Foundation DFG for the kind support within the Cluster of Excellence „Integrative Production Technology for High-Wage Countries.

\section{References}

1. Kagermann, H., Anderl, R., Gausemeier, J., Schuh, G.: Industrie 4.0 im globalen Kontext. Strategien der Zusammenarbeit mit internationalen Partnern. acatech STUDIE. http://www.acatech.de/fileadmin/user_upload/Baumstruktur_nach_Website/Acatech/root/de/Publikationen/Projektberichte/aca-

tech_de_STUDIE_Industrie40_global_Web.pdf (2016). Accessed 28 February 2018

2. Pellengahr, K., Schulte, A.T., Richard, J., Berg, M.: Pilot Study on Procurement 4.0. The Digitalisation of Procurement, Frankfurt a.M. (2016)

3. Glas, D.A., Kleemann, P.D.: The Impact of Industry 4.0 on Procurement and Supply Chain Management: A Conceptual and Qualitative Analysis. International Journal of Business and Management Invention 5(6) (2016)

4. Schuh, G., Walendzik, P., Luckert, M., Birkmeier, M., Weber, A., Blum, M.: Keine Industrie 4.0 ohne den Digitalen Schatten. ZWF (2016). doi: 10.3139/104.111613

5. Biedermann, H.: Ersatzteilmanagement. Effiziente ersatzteillogistik fur industrieunternehmen. Springer, [Place of publication not identified] (2008)

6. Engroff, B.: C-Teile-Management. AWF-Arbeitsgemeinschaft „Die Disposition Strategien, Methoden und Organisation für eine effiziente und prozessorientierte Disposition“. https://www.awf.de/wp-content/uploads/2014/12/C-Teilemanagement-awf.pdf (2014)

7. Knabke, T., Olbrich, S.: Towards Agile BI: Applying In-Memory Technology to Data Warehouse Architectures. Innovative Unternehmensanwendungen mit In-Memory Data Management (2011)

8. FAIR ISAAC Coorporation: Business Intelligence and Big Data Analytics: Speeding the Cycle from Insights to Action Four Steps to More Profitable Customer Engagement. http://docplayer.net/3343658-Business-intelligence-and-big-data-analytics-speeding-the-cycle-from-insights-to-action-four-steps-to-more-profitable-customer-engagement.html. Accessed 15 March 2018

9. Sherman, R.: Business intelligence guidebook. From data integration to analytics. Morgan Kaufmann, Waltham, MA (2015)

10. Bauernhansl, T., Krüger, J., Reinhart, G., Schuh, G.: WGP-Standpunkt Industrie 4.0. https://www.ipa.fraunhofer.de/content/dam/ipa/de/documents/Presse/Presseinformationen/2016/Juni/WGP_Standpunkt_Industrie_40.pdf

11. Schuh, G., Blum, M.: Design of a Data Structure for the Order Processing as a Basis for Data Analytics Methods. http://www.picmet.org/db/member/proceedings/2016/data/polopoly_fs/1.3251052.1472157052!/fileserver/file/680707/filename/16R0290.pdf (2016). Accessed 7 March 2017

12. APICS SCC: Supply Chain Reference model (SCOR). https://www.apics.org/about/overview/about-apics-scc 